\title{
La lógica de construcción en los diseños de la pintura mural de los Hipogeos de Tierradentro, Cauca ${ }^{1}$
}

\author{
The logic of construction in the mural painting \\ designs of Hypogea Tierradentro, Cauca
}

A lógica de construção nos projetos da pintura mural da Hypogea Tierradentro, Cauca

Recibido: mayo 2013

Aceptado: agosto 2013

Armando Aroca Araújoº

\begin{abstract}
Resumen
El presente trabajo de investigación se centra en la lógica de construcción en los diseños de la pintura mural de los Hipogeos de Tierraadetro en el Cauca, en él se destaca la importancia de las matemáticas escolares, las formas geométricas.
\end{abstract}

Palabras clave: Matemáticas escolares; Geometría; Formas Geométricas; Matemáticas desde otras disciplinas; Hipogeos; Lógica de construcción.

\begin{abstract}
TThis research work focuses on building logic in the design of the mural of Hypogea of Tierraadetro in Cauca, it highlights the importance of school mathematics, geometric shapes.
\end{abstract}

Key words: school Mathematics, Geometry, Geometric Shapes, Mathematics in other disciplines; Hypogea; logic construction

\section{Resumo}

Este trabalho de investigação centra-se na lógica de construção na concepção do mural de Hypogea de Tierraadetro em Cauca, ele destaca a importância da matemática escolar, formas geométricas.

Palavras-chave: Matemática da escola, geometria, formas geométricas, Matemática em outras disciplinas; Hipogeus, construção lógica.

\section{Introducción}

El Parque Arqueológico de Tierradentro está localizado en la Cordillera Central de Colombia, esencialmente en las estribaciones de la población de San Andrés de Pisimbalá del departamento del
Cauca. Estos vestigios arqueológicos, considerados por antropólogos o arqueólogos como tumbas secundarias u osarios (hipogeos), fueron declarados en 1995 por la Unesco como Patrimonio de la Humanidad y están conformados por cinco estaciones, Segovia, El Duende, Alto de San Andrés

1 Artículo de Investigación

2 Universidad del Atlántico. Colombia. Contacto: armandoaroca@mail.unitlantico.edu.co 


\section{Marco teórico}

Estos hipogeos, según el consenso académico, han sido analizados desde diferentes perspectivas, antropología, arqueología, arquitectura y artes, de cuyas investigaciones se podrían destacar Burg (1936), Barradas (1937); los diversos informes y dibujos lamentablemente linealizados $^{3}$ por Hernández de Alba (1937) $)^{4}$, Celis (1943), Nachtigall (1956), Ayala (1983a, 1986), Gamboa (1983, 1985), Chávez \& Puerta (1986), Groot (1989); la Unesco (1995), Sevilla (2008b, 2009), la sistematización organizada de los hipogeos que se presenta en www.tierradentro.info del profesor Sevilla y la página web del Instituto Colombiano de Antropología e Historia, ICAHN. En estas investigaciones o análisis se presentan expresiones como "decoración geométrica", "motivos geométricos", "pintura mural", "geometría", "geometría lineal", "figuras geométricas", "simetría” y una del ICAHN, http://www.icanh.gov.co/index.php?idcategoria=2560: "La decoración de las sepulturas consiste en una combinación de escultura y pintura con cavidades circulares rellenas de pintura". ¿Pero a qué se hace referencia concretamente cuando se emplean estas expresiones? Hasta el momento no se había hecho un estudio sistemático de este tipo excepto descriptivo, es decir, uno que tome como objeto de estudio la configuración geométrica que aún se nota en la ornamentación-simbólica del interior de los hipogeos tanto en sus columnas, pilastras, nichos, paredes, techos y cornisas.

\section{Conclusiones.}

La forma que se empleó fue justamente partir del mismo diseño y la arquitectura interna de los hipogeos que fue descrita por Ayala (1986). Fue así como se establecieron cuatro categorías de análisis: Franjas de separación, Patrón Figural, Direccionalidad y Configuración mínima, como se muestra en la Figura 1. Y da la sensación que este es el orden con que se desarrolla el diseño.
Figura 1. Algunas nociones geométricas en la configuración de los diseños.

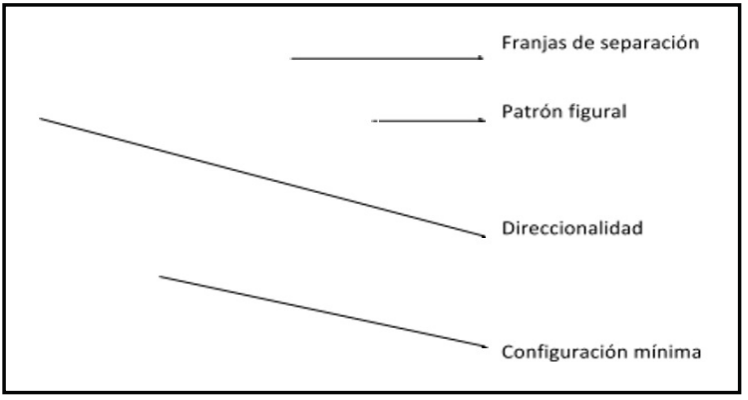

Fuente: Elaboración propia

El rombo, o mejor romboide para este caso, es la figura geométrica de mayor empleo en los diseños. Él, no siempre fue creado como unidad sino que apareció como consecuencia de alguna construcción geométrica, es decir, aparecían por la interceptación de la familia de líneas paralelas oblicuas hacia la izquierda al interceptarse con la familia de líneas paralelas oblicuas hacia la derecha, aunque dependiendo la estructura del hipogeo esto puede cambiar. Estos romboides manejan distintos grados de nivel de concentricidad y combinación tanto cromática como de poligonales y superficies, como se puede ver, a manera de muestra, en la siguiente Figura.

Figura 2. Algunas configuraciones con romboides que se encuentran en el Parque.

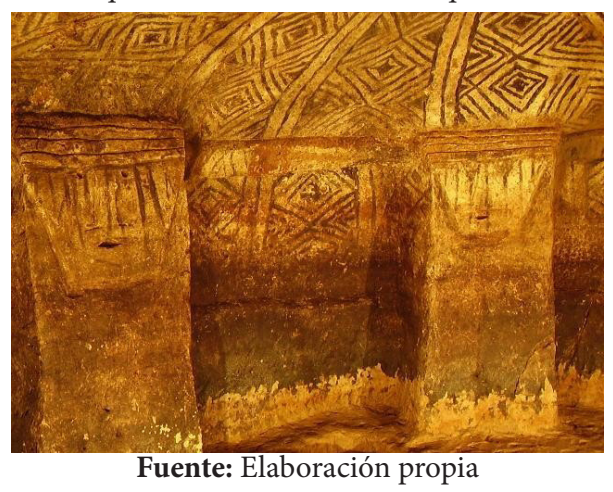

Las cornisas y los techos de los hipogeos y pedazos de la superficie que aún han soportado el embate del tiempo, debelan otros niveles de amplificación de los romboides. Da entonces la impresión que hay un nivel infinito, tanto para el color negro

3 Por haber incurrido en la linealización de los diseños, Hernández de Alba presenta dibujos o representaciones de los interiores de varios hipogeos que poco contribuyen para acercarnos a la lógica de construcción de los mismos.

4 Estos dibujos solo pueden ser consultados en sala, en la Biblioteca Luis Ángel Arango. 
como para el color rojo, sin combinarse entre sí, y esto se encuentra en el techo, al interior de la cornisa, del hipogeo NS23.

Tomando como referencia el modelo de Velandia (1994) para la combinación del color en la estatuaria de San Agustín, se podría entonces plantear
Figura 3. Las fórmulas de combinación de colores en los patrones figurales en los hipogeos.

\begin{tabular}{|l|l|l|l|l|l|}
\hline NS23 $^{4}$ & NSA1 & NA11 & NSA1 & NSA5 & NSA6 \\
& & & & & \\
\hline
\end{tabular}

Fuente: Elaboración propia

Figura 4. La fórmula de combinación de colores en los romboides concéntricos del Parque Arqueológico de Tierradentro, presente en cada estación.

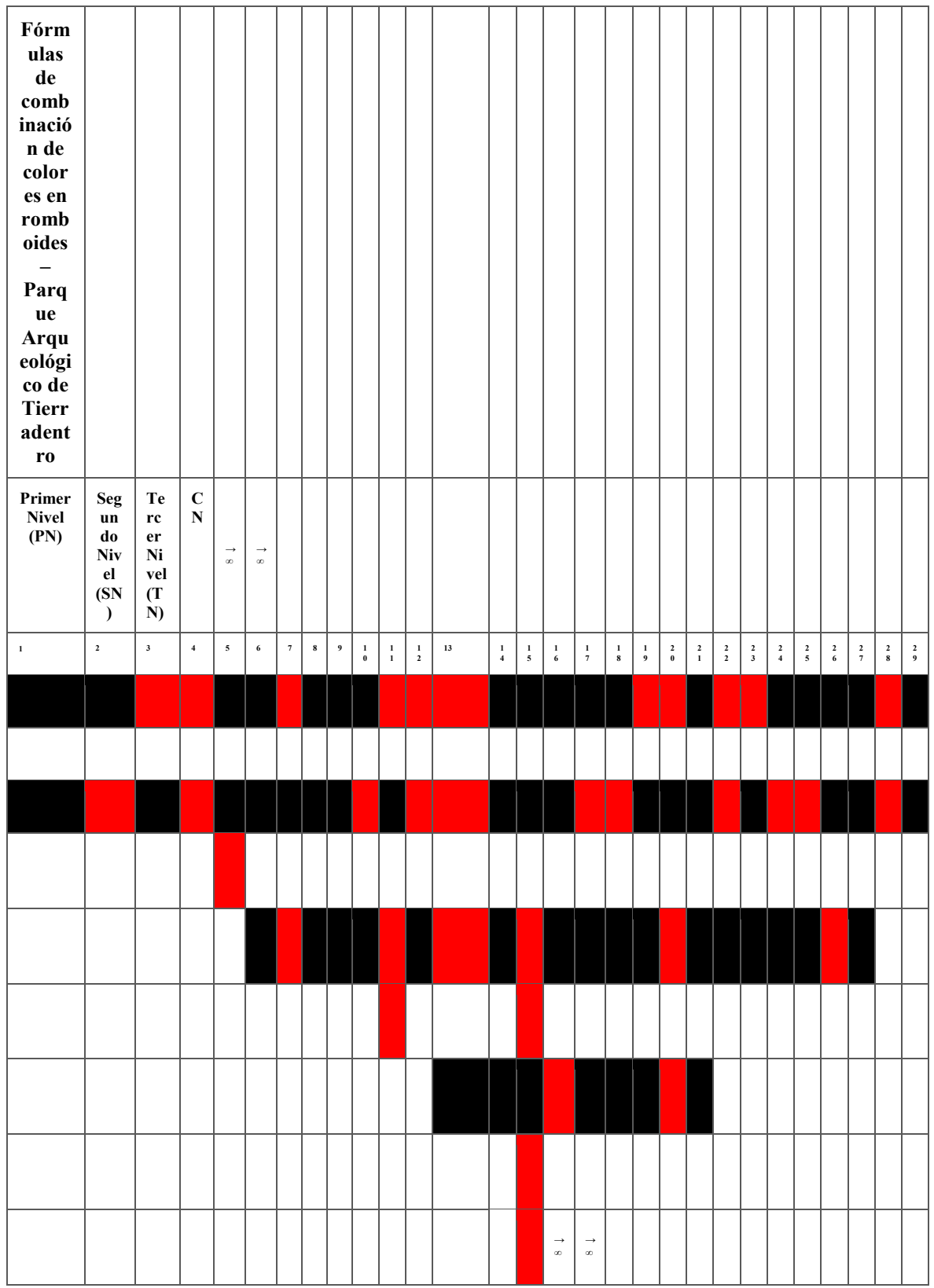

Fuente: Elaboración propia

5 Estos códigos que se emplean para referenciar los hipogeos y que se encuentran en www.tierradentro.info 
las fórmulas de combinación de colores que se encuentran en los hipogeos de Tierradentro.

Velandia (1994), determinó que la cultura de San Agustín empleó cuatro colores, los tres que emplearon en Tierradentro más el amarillo ocre, y pudo establecer nueve fórmulas de combinaciones. En Tierradentro, solo tomando los romboides concéntricos al interior de los hipogeos, que emplearon tres colores, se pudo determinar que por ahora son 29 fórmulas.

Por último se plantean algunas síntesis que son motivo de discusión.

1. Las personas encargadas de hacer los diseños en la pintura mural de los hipogeos de Tierradentro, eran especializados en esta función.

2. Estos artesanos geómetras planificaban, incluso con mucho detalle y paciencia, el diseño de toda la superficie interna del hipogeo. Es decir, había conciencia de la aplicación de nociones métricas y de herramientas.

3. En estos diseños se emplearon herramientas geométricas o de medición que hoy día la arqueología no las ha evidenciado.

4. Estos diseños se constituyen en una de la expresiones de un pensamiento geométrico y métrico, más auténtica del Patrimonio Matemático Nacional.

5. La única fórmula que se puede encontrar en cada una de las estaciones es la F8, pero no hay ninguna que sea transversal a cada uno de los hipogeos.

\section{Referencias}

Aroca, A. (2007). Geometría en las mochilas arhuacas. Por una enseñanza de la geometría desde una perspectiva cultural. Cali: Editorial Universidad del Valle.
Pérez de Barradas, J. (1937). Arqueología y antropología de Tierradentro. Bogotá: Imprenta Nacional.

Ayala, L. (1986). Las tumbas pintadas de Tierradentro. En: E. Barney Cabrera (Org.). Historia del Arte Colombiano. Vol. I. p. 188212. Bogotá: Salvat Editores.

Ayala, L. (1983a). Tierradentro, la Serranía de los Muertos. En: E. Barney Cabrera (Org.). Historia del Arte Colombiano. Vol. II 149188. Bogotá: Salvat Editores.

Bishop, A. (1999). Enculturación matemática. Capítulo 2. Argentina: Ibérica S.A./ Paídos, SAICF.

Celis, E. (1943). La arqueología de Tierradentro. Revista del Instituto Etnológico Nacional, 1: 117-130.

Chávez, M. (1981). Los animales mágicos en las urnas de Tierradentro. Bogotá: Museo de Artes y Tradiciones populares.

Chávez, A. \& Puerta, M. (1986.) Monumentos arqueológicos de Tierradentro. Bogotá: Talleres gráficos, Banco Pupolar.

Duque, L. \& Cubillos, J. (1976). Arqueología de San Agustín: Alto de los Ídolos, Montículos $y$ Tumbas. Bogotá: Fundación de Investigaciones Arqueológicas Nacionales Banco de la República.

Duque, L. (1995). Monumentos y objetos arqueológicos. Tomo I. México: Instituto panamericano de geografía e historia.

Gamboa, P. (1983). Tierradentro. Los constructores de hipogeos. Revista de Extensión Cultural. 15: 6-15

Gamboa, P. (1985). El arte de tierradentro. Revista de la Universidad Nacional 1(1): 43-48.

Gerdes, P. (1989). Sobre aritmética e ornamentação geométrica. Análise de alguns cestos de índios do Brasil. Boletim de educaçao matemática, BOLEMA Especial. 1: 11-34. 
Gerdes, P. (2003). Sobre o despertar do pensamento geométrico. (2nd Edit.). Curitiba: Universidade Federal de Paraná.

Gerdes, P. (2000a). Le cercle et le carré: Créativité géométrique, artistique, et symbolique de vannières et vanniers d'Afrique, d'Amérique, d'Asie et d'Océanie. Paris: L'Harmattan

Hernández de Alba, G. (1942). Expedición del Instituto Etnológico Nacional a la región de Tierradentro. Archivo fotográfico y diversos reportes. Bogotá: Biblioteca Luis Ángel Arango, Banco de la república.

Mariño, R. (2004). La geometría en el arte y el diseño. Bogotá: Universidad Nacional de Colombia. Pro-offset editorial Ltda.

Sevilla, E. (2008). Tierradentro: Les arts premiers y la jigra de la vida. En: Ensayo sobre arte contemporáneo en Colombia. Bogotá: Universidad de los Andes.

Sevilla, E. (2008). Tierradentro: les arts premiers y la jigra de la vida”. En: Universidad de los Andes y Ministerio de Cultura (Eds.) Ensayos sobre arte contemporáneo en Colombia. Bogotá: Universidad de los Andes.

Sevilla, E. (2009). Informe final del Proyecto Tierradentro, No. 398. Bogotá: Banco de la República, Fundación de Investigaciones Arqueológicas Nacionales, FIAN.

Velandia, C. (1994). SAN AGUSTÍN. Arte, estructura y arqueología. Bogotá: Editorial Presencia.

Nachtigall, G. (1956). Tierradentro. Studia. 1(10): 21-55. 